\title{
Regular Uterine Contraction
}

National Cancer Institute

\section{Source}

National Cancer Institute. Regular Uterine Contraction. NCI Thesaurus. Code C92867.

A consistent rhythmic pattern of uterine muscle tightening that occurs at regular intervals for the same duration of time. 